\title{
Frequency Responses of Ground-Penetrating Radars Operating Over Highly Lossy Grounds
}

\author{
Uğur Oğuz and Levent Gürel, Senior Member, IEEE
}

\begin{abstract}
The finite-difference time-domain (FDTD) method is used to investigate the effects of highly lossy grounds and the frequency-band selection on ground-penetrating-radar (GPR) signals. The ground is modeled as a heterogeneous half space with arbitrary background permittivity and conductivity. The heterogeneities encompass both embedded scatterers and surface holes, which model the surface roughness. The decay of the waves in relation to the conductivity of the ground is demonstrated. The detectability of the buried targets is investigated with respect to the operating frequency of the GPR, the background conductivity of the ground, the density of the conducting inhomogeneities in the ground, and the surface roughness. The GPR is modeled as transmitting and receiving antennas isolated by conducting shields, whose inner walls are coated with absorbers simulated by perfectly matched layers (PML). The feed of the transmitter is modeled by a single-cell dipole with constant current density in its volume. The time variation of the current density is selected as a smooth pulse with arbitrary center frequency, which is referred to as the operating frequency of the GPR.
\end{abstract}

Index Terms-Finite-difference time-domain (FDTD) method, ground conductivity, ground-penetrating radar (GPR), perfectly matched layer (PML).

\section{INTRODUCTION}

$\mathbf{T}$ HE interest in the responses of ground-penetrating radars (GPRs) to different types of soils [1]-[4] has been growing rapidly. Especially, the employment of the finite-difference time-domain (FDTD) [5] method has been an important factor in the increase of the reported GPR simulations in the literature [6]-[8]. The FDTD method has been used to simulate GPR problems containing various types of soils: lossy, heterogeneous, and dispersive. In the reports found in the literature, it is shown that the FDTD method has the capability of modeling a wide range of realistic soil parameters. This paper presents the results of a series of GPR simulations modeling highly conductive and heterogeneous soils. The goal of this paper is to investigate the response of a GPR as a function of two variables, which are the operating frequency and the ground conductivity, while considering the ground inhomogeneity as a parameter.

A typical GPR scenario consists of air, modeled by vacuum in this paper, ground, modeled by heterogeneous and lossy dielectric half-space, GPR unit, containing transmitting and receiving antennas, and the buried targets, modeled by rectangular

Manuscript received September 8, 2001; revised April 10, 2002. This work was supported by Bilkent University under Research Fund EE-01-01.

U. Oğuz was with the Department of Electrical and Electronics Engineering, Bilkent University, Ankara TR-06533, Turkey. He is now with Tübitak-Uekae, Ankara, Turkey.

L. Gürel is with the Department of Electrical and Electronics Engineering, Bilkent University, Ankara TR-06533, Turkey.

Publisher Item Identifier 10.1109/TGRS.2002.800437.

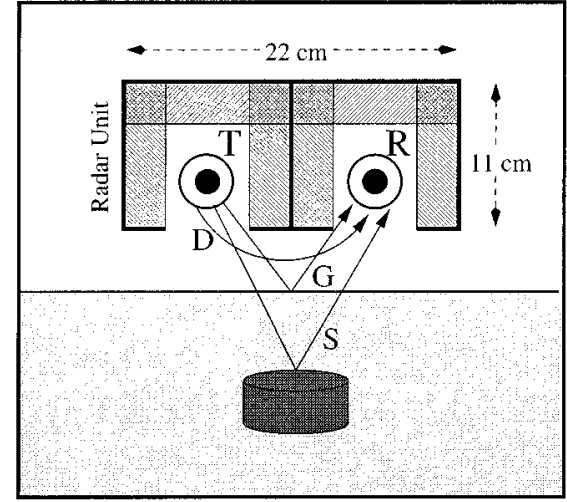

Fig. 1. Typical GPR problem and the GPR configuration with a transmitter and a receiver. The total received signal is an aggregate of three signals: the direct signal (D) coupled from the transmitter to the receiver, the signal reflected from the ground $(\mathrm{G})$, and the signal scattered by the buried target (S).

prisms and cylindrical disks of arbitrary conductivity and permittivity. Fig. 1 depicts such a typical GPR scenario. The GPR unit presented in Fig. 1 and modeled in this paper contains a transmitter and a receiver, which are isolated by shields in order to reduce the large direct coupling (D in Fig. 1) observed at the receiver location [9]-[11]. Absorbers, which are simulated by perfectly-matched-layer (PML) absorbing boundary conditions (ABCs) [12], are mounted on the inner shield walls, in order to reduce the ringing effects [9]-[11]. The near-field pattern of this GPR model ([2], Fig. 3), ([9], Fig. 6) has the desired directive properties of a typical GPR antenna. The PML ABC is also used to terminate the FDTD grid, matching the ground, the air, and the interface between them [13], [14].

The feed of the transmitting antenna is an $x$-polarized dipole, modeled by a single Yee cube of constant current density in its volume [15]. The receiver is also modeled as a small dipole that samples the $x$ component of the electric-field function, $E_{x}(x, y, z, t)$, with a sampling period of $\Delta t$ in time. The time variation of the current source on the transmitter feed is given by [16]

$$
J(t)=\frac{1}{\Delta^{3}}\left[4\left(\frac{t}{\tau}\right)^{3}-\left(\frac{t}{\tau}\right)^{4}\right] e^{-\frac{t}{\tau}}
$$

where $\tau=1 /\left(4 \pi f_{0}\right), f_{0}$ is the center frequency of the pulse, and $\Delta$ and $\Delta t$ are the spatial and temporal sampling intervals, respectively. Plots of (1) for $f_{0}=500 \mathrm{MHz}$ in time and frequency domains are presented in ([9], Fig. 3).

When the radar unit is stationary and the receiver collects data at a point $\left(x_{0}, y_{0}, z_{0}\right)$ in space for successive instants of time, 
this is called an A-scan. A B-scan is obtained by performing repeated A-scan measurements at discrete points on a linear path. In the following sections of this paper, many A-scan and B-scan simulation results will be presented in order to demonstrate the effects of ground loss in GPR measurements. In these simulations, the ground is modeled by a heterogeneous and lossy dielectric half-space. The background permittivity of the ground is set as $8 \epsilon_{0}$, and the conductivity varies arbitrarily throughout the paper. Lossy dielectric scatterers, with randomly selected sizes, locations, permittivities, and conductivities, are embedded in the ground in order to provide the heterogeneity. The density of these scatterers is higher in the upper level of the ground model. Since the small conducting scatterers contribute to the overall conductivity of the soil model, the upper level of the ground can be considered as more lossy than the lower level.

In addition to the buried scatterers, a number of randomly distributed "scatterers" with electromagnetic properties of vacuum are defined on the ground-air interface. These "scatterers" with $\epsilon_{0}$ permittivity and zero conductivity alter the smooth characteristics of the ground-air interface and simulate surface roughness, which is an important feature of real-life soils that should not be ignored. The effects of heterogeneous ground models have been studied extensively and reported in the literature [2], [3].

\section{Properties of Lossy Grounds}

Although real-life soils have frequency-dependent permittivity and conductivity values, experiments have shown that the electrical parameters of the ground do not change very rapidly with the frequency of the incident wave [17], [18]. However, two parameters of the source signal should be carefully set in order to make sure that the ground parameters are constant in the band of transmission. First of these parameters is the bandwidth of the source signal. When the source signal used to illuminate the ground is not a wide-band signal, it is possible to assume that the electrical parameters of the ground are the same for all frequency components. However, experiments show that there are transition bands of real-life soils, where the permittivity and conductivity values encounter a more rapid change [18]. If the center frequency of the source signal, which is the second important parameter, is not set in this transition band, then the permittivity and the conductivity of the ground is again almost constant for all frequency components of the signal.

Although the electrical parameters $\epsilon$ and $\sigma$ are independent of the frequency, lossy grounds and their surfaces still yield different reflection and transmission coefficients for different frequency components. A useful parameter for the investigation of the relation between conductivity and frequency is the skin depth, $\delta$, the distance through which the amplitude of a traveling wave decreases by a factor of $e^{-1}$ [19]. The skin depth is given by

$$
\delta=1 / \operatorname{Im}\left(w\left[\mu\left(\epsilon+i \frac{\sigma}{w}\right)\right]^{1 / 2}\right)
$$

where $w=2 \pi f$ and $\epsilon, \mu$, and $\sigma$ are respectively the permittivity, permeability, and the conductivity of the media. In this paper, the permittivity and the permeability values of all ground models are set as $8 \epsilon_{0}$ and $\mu_{0}$, respectively. Fig. 2 displays the

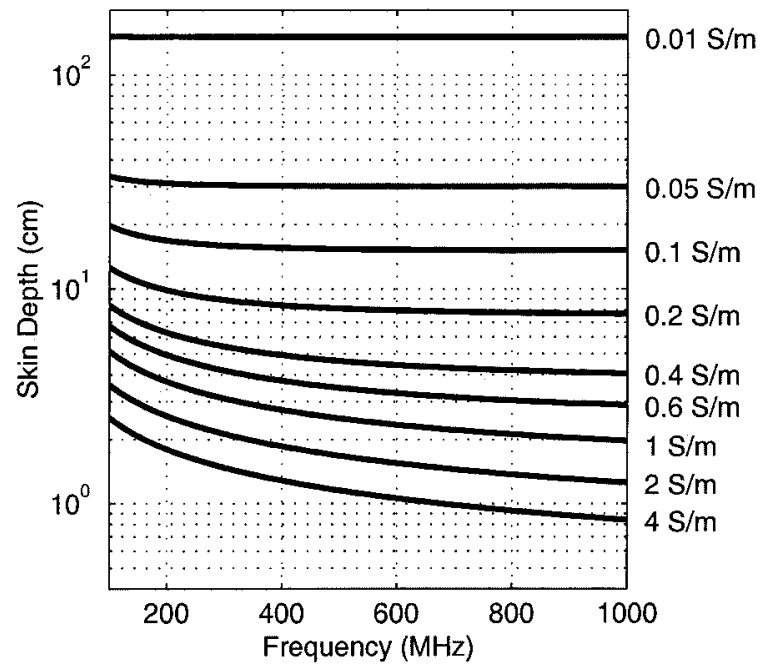

Fig. 2. Skin-depth values of a ground model with $8 \epsilon_{0}$ permittivity and $\mu_{0}$ permeability in the frequency band $100 \mathrm{MHz}-1 \mathrm{GHz}$. The conductivity of the soil is varied from $0.01 \mathrm{~S} / \mathrm{m}$ to $4.0 \mathrm{~S} / \mathrm{m}$.

skin-depth values in the frequency band of $100 \mathrm{MHz}-1 \mathrm{GHz}$ for ground conductivity values of $0.01 \mathrm{~S} / \mathrm{m}, 0.05 \mathrm{~S} / \mathrm{m}, 0.1 \mathrm{~S} / \mathrm{m}$, $0.2 \mathrm{~S} / \mathrm{m}, 0.4 \mathrm{~S} / \mathrm{m}, 0.6 \mathrm{~S} / \mathrm{m}, 0.8 \mathrm{~S} / \mathrm{m}, 1.0 \mathrm{~S} / \mathrm{m}, 2.0 \mathrm{~S} / \mathrm{m}$, and 4.0 S/m. Fig. 2 demonstrates that the skin depth of the ground stays almost constant in this frequency band for the conductivity values below $0.1 \mathrm{~S} / \mathrm{m}$. However, the other curves in the same plot demonstrate that for $0.2 \mathrm{~S} / \mathrm{m}$ and higher conductivity values, the skin-depth values are subject to a relatively more rapid change in the $100 \mathrm{MHz}-1 \mathrm{GHz}$ frequency band, although, they are in the order of centimeters.

The following sections present simulation results of highly conductive ground models obtained with the smooth source function at various center frequencies. In order to assure the accuracy of the simulation results, the higher the frequencies and the conductivities are simulated, the finer $\Delta$ and $\Delta t$ should be chosen [20].

\section{A-ScAn Results}

In this section, the results of simulations performed at a stationary point above the ground, i.e., A-scan results, will be presented to demonstrate the relations between the ground conductivity and center frequency of the source signal. First, in Section III-A, a set of simulations with a fixed source signal will be presented in order to demonstrate only the effects of the conductivity. Then, in Section III-B, the effects of changing the center frequency of the source signal for a fixed ground conductivity will be demonstrated.

\section{A. Effect of the Conductivity at a Fixed Frequency}

The ground conductivity affects both $\mathrm{G}$ and $\mathrm{S}$ signals, i.e., the signals reflected from the ground-air interface and the signals scattered from the target. The increase in the conductivity increases the reflection from the ground-air interface, and thus, yields a larger $\mathrm{G}$ signal. Since the $\mathrm{G}$ signal is retarded in time with respect to the $\mathrm{D}$ signal, a larger $\mathrm{G}$ signal implies a longer tail for the total background signal, $\mathrm{D}+\mathrm{G}$. Thus, humid soils make it harder to detect the $\mathrm{S}$ signal in $\mathrm{D}+\mathrm{G}+\mathrm{S}$. 


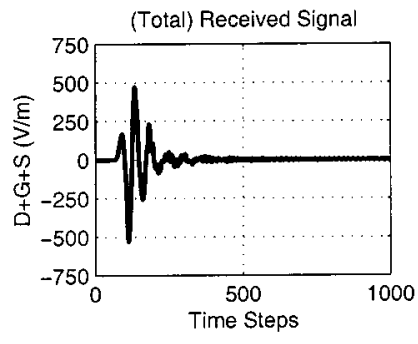

(a)

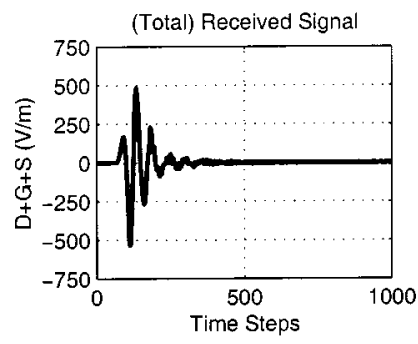

(c)

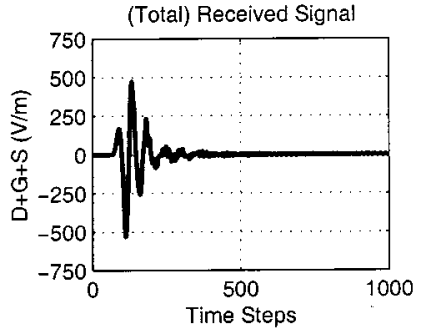

(b)

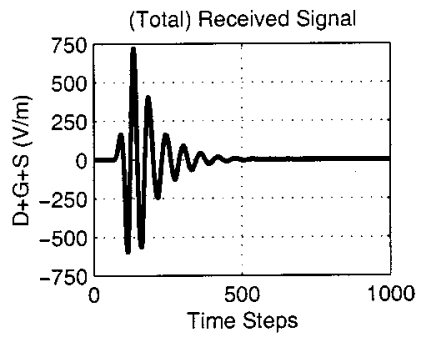

(d)
Fig. 3. Effects of the ground conductivity on the total-received signal. The GPR unit records the signals at an elevation of $7.5 \mathrm{~cm}$ above the homogeneous ground models with conductivities (a) $0.001 \mathrm{~S} / \mathrm{m}$, (b) $0.01 \mathrm{~S} / \mathrm{m}$, (c) $0.1 \mathrm{~S} / \mathrm{m}$, and (d) $1.0 \mathrm{~S} / \mathrm{m}$. The ground has a permittivity of $8 \epsilon_{0}$.

The increase in the amplitude and tail of the $\mathrm{D}+\mathrm{G}$ signal with increased conductivity is demonstrated by the simulation results given in Fig. 3. In these simulations, the GPR unit, operating at $500 \mathrm{MHz}$, records the raw received signals at an elevation of $7.5 \mathrm{~cm}$ above four ground models. These ground models are target-free homogeneous dielectric half-spaces with conductivities $0.001 \mathrm{~S} / \mathrm{m}, 0.01 \mathrm{~S} / \mathrm{m}, 0.1 \mathrm{~S} / \mathrm{m}$, and $1.0 \mathrm{~S} / \mathrm{m}$. Assuming single frequency component and normal incidence to the ground, the Fresnel reflection coefficients from the interface are $0.523,0.535,0.808$, and 0.995. Fig. 3(a)-(c) display the simulation results obtained with $0.001 \mathrm{~S} / \mathrm{m}, 0.01 \mathrm{~S} / \mathrm{m}$, and $0.1 \mathrm{~S} / \mathrm{m}$ conductivities, respectively. These three plots exhibit almost no difference, revealing that the reflections from the ground-air interface are almost the same for conductivities of $0.001 \mathrm{~S} / \mathrm{m}$, $0.01 \mathrm{~S} / \mathrm{m}$, and $0.1 \mathrm{~S} / \mathrm{m}$, at a center frequency of $500 \mathrm{MHz}$. However, the ground model with a conductivity of $1.0 \mathrm{~S} / \mathrm{m}$ induces a large reflection, amplifying the total signal and its tail, as seen in Fig. 3(d). Since the theoretical reflection coefficient becomes nearly unity at this conductivity level, this increase in the ground reflection is predictable.

The more important impact of the ground conductivity is on the $\mathrm{S}$ signal, which is the signal scattered from the target. The only signal that encounters continuous decay due to loss is the signal penetrating the ground and reflecting from the scatterer to reach the receiver. Therefore, the waves that reach the target buried in a humid soil are much weaker than the waves that penetrate to the same depth in a dry soil. Noting the waves reflected from the target encounter the same amount of decay while they propagate back to the ground-air interface, the significance of the ground conductivity on GPR performance becomes apparent. The effect of the ground decay is demonstrated in ([2], Fig. 4), where it is observed that the conductivity values $0.001 \mathrm{~S} / \mathrm{m}$ and $0.01 \mathrm{~S} / \mathrm{m}$ cause almost no attenuation on the scat-
$200 \mathrm{MHz}$

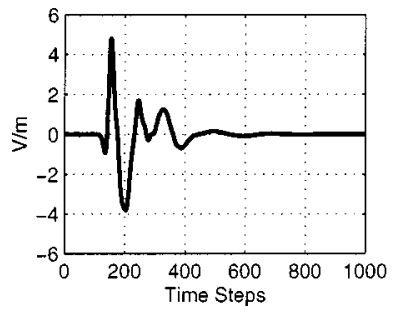

(a)

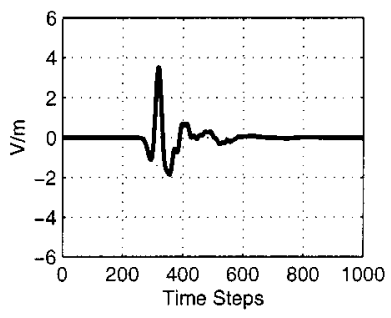

(c)
$1000 \mathrm{MHz}$

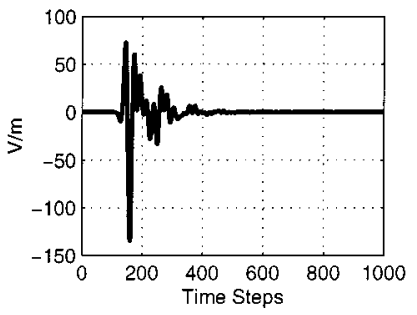

(b)

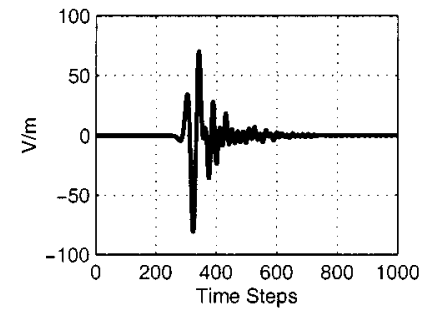

(d)
Fig. 4. Scattered signals collected by GPR units above a ground of $0.1 \mathrm{~S} / \mathrm{m}$ conductivity. The center frequencies of the GPR signals are $200 \mathrm{MHz}$ in (a) and (c), and $1000 \mathrm{MHz}$ in (b) and (d). The target is a perfectly conducting disk with $2.5 \mathrm{~cm}$ radius and $4 \mathrm{~cm}$ height buried $2.5 \mathrm{~cm}$ in (a) and (b), and $10 \mathrm{~cm}$ in (c) and (d), under the ground-air interface.

tered signals. However, when the conductivity is increased to $0.1 \mathrm{~S} / \mathrm{m}$ and values larger than that, the amplitude of the $\mathrm{S}$ signal decreases rapidly. Therefore, ground models with conductivity values below $0.1 \mathrm{~S} / \mathrm{m}$ may be regarded as dry at the center frequency of $500 \mathrm{MHz}$.

\section{B. Effect of the Frequency}

In this section, simulation results of a conducting disk, modeled with contour-path algorithms [21] and buried in a homogeneous ground model, will be given for center frequencies of the source signal between $200 \mathrm{MHz}$ and $1000 \mathrm{MHz}$. Figs. 4 and 5 display the simulation results obtained with ground conductivities $0.1 \mathrm{~S} / \mathrm{m}$ and $1.0 \mathrm{~S} / \mathrm{m}$, respectively. In these simulations, perfectly conducting disk-shaped targets are buried $2.5 \mathrm{~cm}$ and $10 \mathrm{~cm}$ under the ground with $8 \epsilon_{0}$ permittivity. The scattered signals of 2.5-cm-deep and 10-cm-deep targets are displayed revealing the amount of decay encountered by the incident and scattered waves propagating from $2.5 \mathrm{~cm}$ to $10 \mathrm{~cm}$ into the ground and back.

Fig. 4 demonstrates that for $0.1 \mathrm{~S} / \mathrm{m}$ value of ground conductivity, the amplitudes of the scattered signals are decreased approximately 1.5 times, while the target is moved from $2.5 \mathrm{~cm}$ to $10 \mathrm{~cm}$, for both center frequencies. Whereas, for the ground model with $1.0 \mathrm{~S} / \mathrm{m}$ conductivity, Fig. 5 demonstrates that, at $200 \mathrm{MHz}$, the ratios of the amplitudes of the two scattered signals is approximately $2 \times 10^{3}$. However, at $1000 \mathrm{MHz}$, this ratio increases to $10^{4}$. The ratios deduced from Figs. 4 and 5 lead to the following conclusion: even though it is well known that higher frequencies cause smaller skin depths and faster decays, for the range of practical GPR frequencies and realistic soil conductivities used in Figs. 4 and 5, this is not necessarily always the case. 


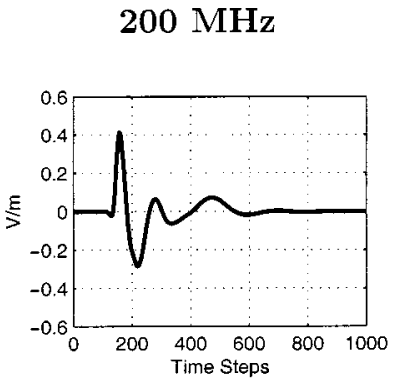

(a)

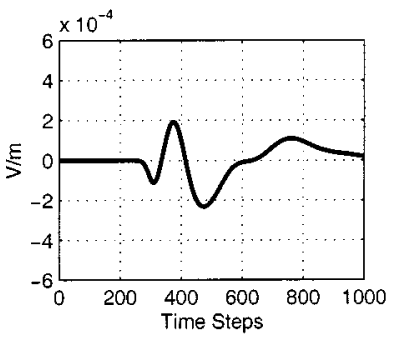

(c)

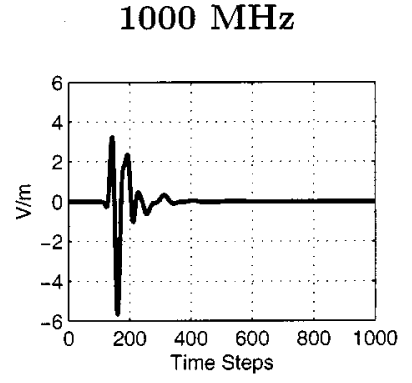

(b)

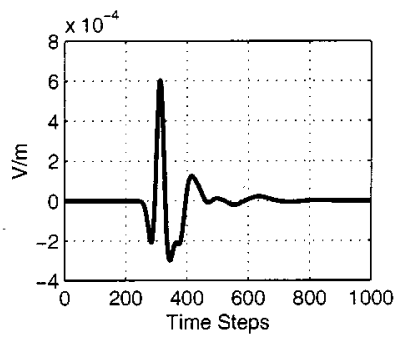

(d)
Fig. 5. Scattered signals collected by GPR units above a ground of $1.0 \mathrm{~S} / \mathrm{m}$ conductivity. The center frequencies of the GPR signals are $200 \mathrm{MHz}$ in (a) and (c), and $1000 \mathrm{MHz}$ in (b) and (d). The target is a perfectly conducting disk with $2.5 \mathrm{~cm}$ radius and $4 \mathrm{~cm}$ height buried $2.5 \mathrm{~cm}$ in (a) and (b), and $10 \mathrm{~cm}$ in (c) and (d), under the ground-air interface.

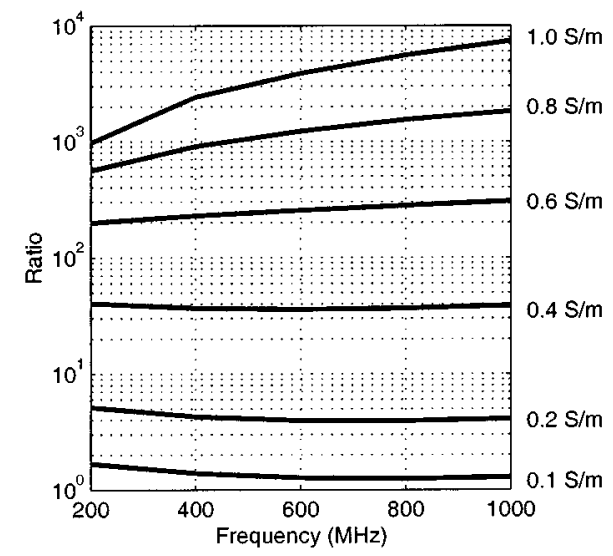

Fig. 6. Ratios of the energies of the $\mathrm{S}$ signals scattered from targets buried 2.5 $\mathrm{cm}$ and $10 \mathrm{~cm}$ under the ground. The permittivity of the ground is $8 \epsilon_{0}$, whereas the conductivity varies as $0.1 \mathrm{~S} / \mathrm{m}, 0.2 \mathrm{~S} / \mathrm{m}, 0.4 \mathrm{~S} / \mathrm{m}, 0.6 \mathrm{~S} / \mathrm{m}, 0.8 \mathrm{~S} / \mathrm{m}$, and 1.0 $\mathrm{S} / \mathrm{m}$. The center frequency of the smooth pulse is set as $200 \mathrm{MHz}, 400 \mathrm{MHz}$, $600 \mathrm{MHz}, 800 \mathrm{MHz}$, and $1000 \mathrm{MHz}$.

In order to further illustrate the effect of the center frequency on the scattered signals, a set of simulations are performed with the same conducting disk buried $2.5 \mathrm{~cm}$ and $10 \mathrm{~cm}$ under different ground models of $0.1 \mathrm{~S} / \mathrm{m}, 0.2 \mathrm{~S} / \mathrm{m}, 0.4 \mathrm{~S} / \mathrm{m}$, $0.6 \mathrm{~S} / \mathrm{m}, 0.8 \mathrm{~S} / \mathrm{m}$, and $1.0 \mathrm{~S} / \mathrm{m}$. For all of these ground-conductivity values, the center frequency of the smooth pulse is changed from $200 \mathrm{MHz}$ to $400 \mathrm{MHz}, 600 \mathrm{MHz}, 800 \mathrm{MHz}$, and $1000 \mathrm{MHz}$. The energies of these 30 scattered signals are computed by

$$
\text { Energy }=\sum_{n}\left|E_{x}^{n}\right|^{2}
$$

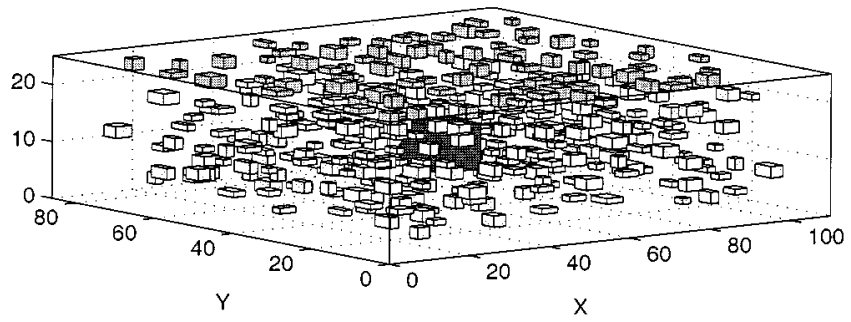

(a)

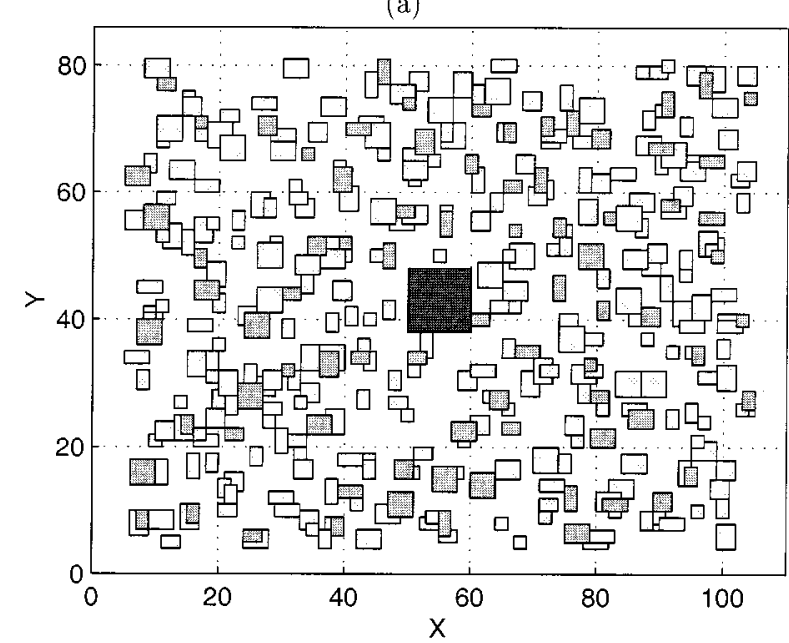

(b)

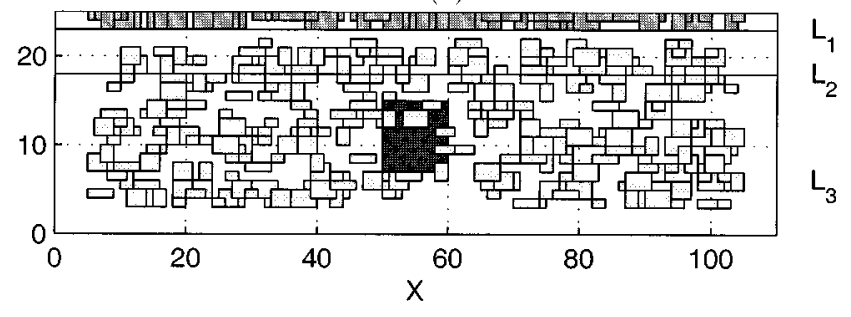

(c)

Fig. 7. Heterogeneous ground model, with a background permittivity value of $8 \epsilon_{0}$. There are 80 holes on the surface of the ground. The second ground level contains 100 highly conducting inhomogeneities and the third level contains 200 scatterers with relatively lower conductivity values. The target is a conducting disk buried $5 \mathrm{~cm}$ deep.

where $E_{x}^{n}$ is the value of the $n$th time step of the $x$ component of the electric field at the location of the receiver. Fig. 6 displays five curves plotted with respect to frequency, illustrating the ratios of these energy values, obtained with the division of the energy of the signal scattered from the $2.5-\mathrm{cm}$-deep target by that of the 10-cm-deep target. Fig. 6 demonstrates that, at $0.1 \mathrm{~S} / \mathrm{m}$, $0.2 \mathrm{~S} / \mathrm{m}$, and $0.4 \mathrm{~S} / \mathrm{m}$ conductivities, the center-frequency values between $200 \mathrm{MHz}$ and $1000 \mathrm{MHz}$ do not reveal any difference in the energy of the scattered signal since the ratios are almost constant. However, from $0.6 \mathrm{~S} / \mathrm{m}$ to $1.0 \mathrm{~S} / \mathrm{m}$, decreasing the center frequency from $1000 \mathrm{MHz}$ to $200 \mathrm{MHz}$ enhances the detectability of the target buried at $10 \mathrm{~cm}$, since the relative scattered energy of the deeper disk is increased.

\section{B-SCAN RESULTS}

In this section, the B-scan simulation results of the conducting disk buried in a highly-conductive heterogeneous ground model 


\section{$200 \mathrm{MHz}$}

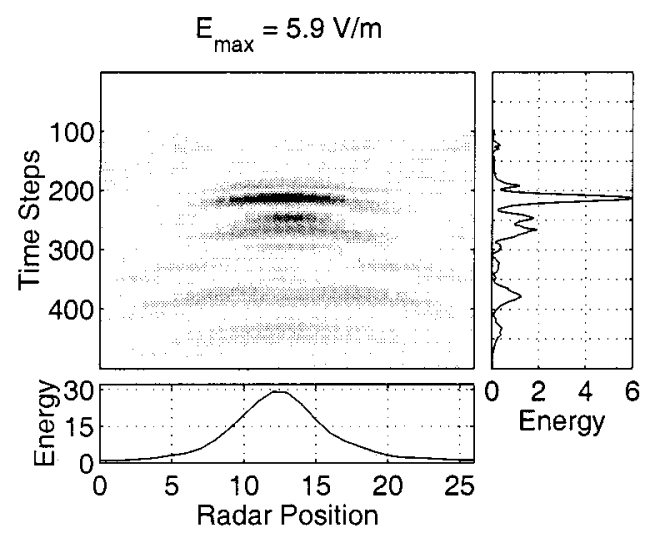

(a)

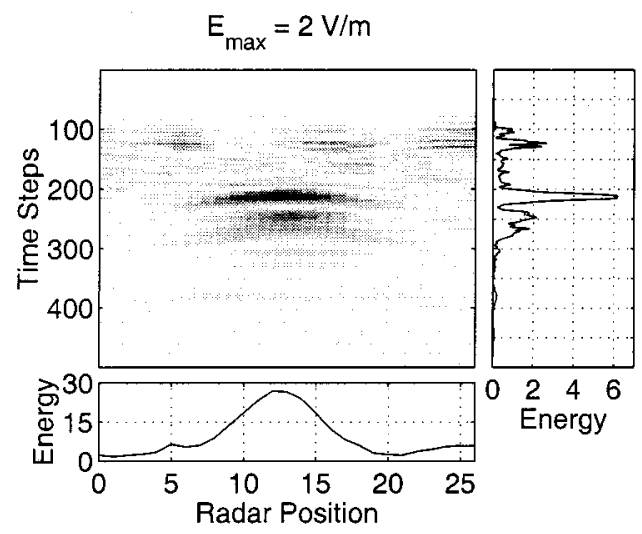

(c)

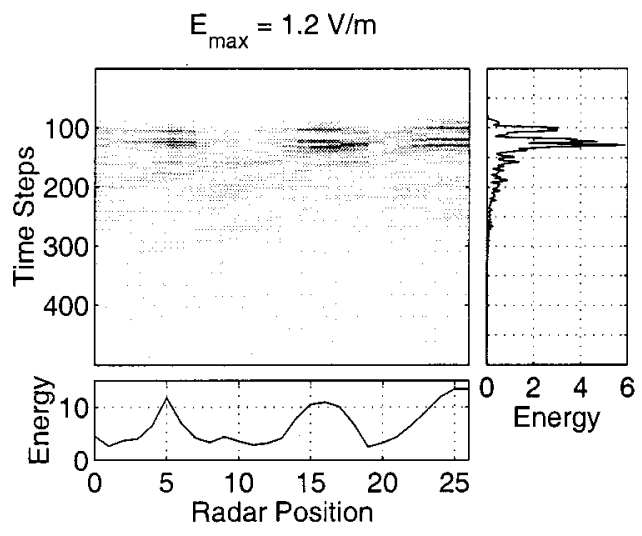

(e)
$1000 \mathrm{MHz}$

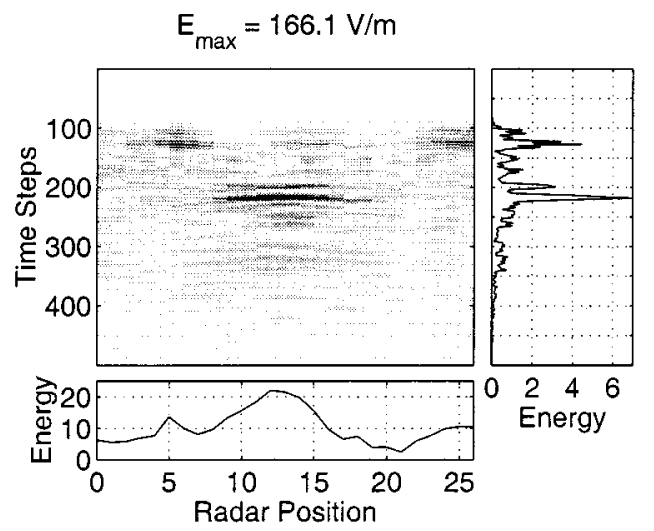

(b)

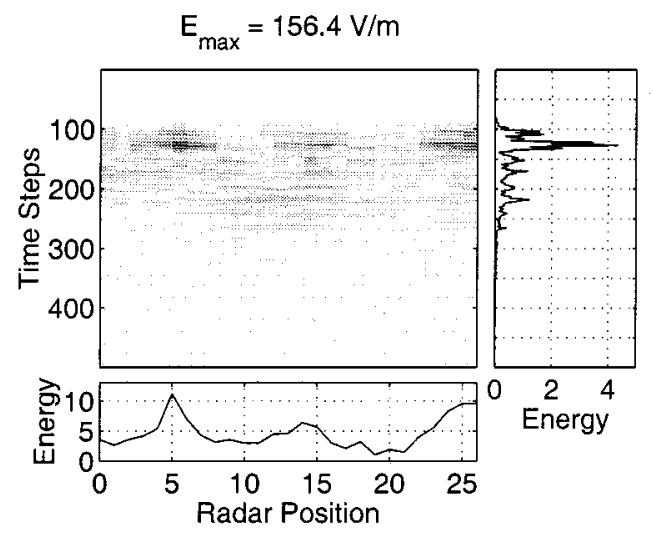

(d)

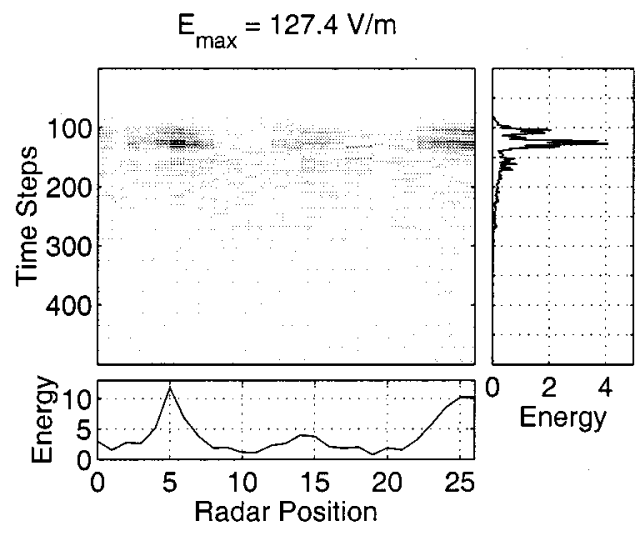

(f)

Fig. 8. Simulation results of a conducting disk buried $5 \mathrm{~cm}$ under the ground-air interface. The permittivity of the ground is $8 \epsilon_{0}$, while the conductivity is 0.05 $\mathrm{S} / \mathrm{m}$ in (a) and (b), $0.2 \mathrm{~S} / \mathrm{m}$ in (c) and (d), and $0.8 \mathrm{~S} / \mathrm{m}$ in (e) and (f). The center frequency of the source signal is $200 \mathrm{MHz}$ in (a), (c), and (e), and $1000 \mathrm{MHz}$ in (b), (d), and (f).

will be given. The GPR unit is described in Section I. The referred ground model, depicted in Fig. 7, is similar to the densely inhomogeneous ground model introduced in [2]. There are 80 holes on the surface $\left(L_{1}\right)$ of the ground, which models the surface roughness of realistic ground-air interfaces. Additionally, there are 100 highly conducting small scatterers embedded in the upper level $\left(L_{2}\right)$ and 200 relatively less conducting small scatterers buried in the lower level $\left(L_{3}\right)$ of the ground model. Although it is possible to model the surface roughness and the ground heterogeneities more precisely by contour-path FDTD algorithms [21], it is shown in the literature that staircase modeling of a surface with statistical distribution of scatterers produces very similar results to both contour-path FDTD and integral-equation solutions of the same ground [3]. The target, 
which is modeled using contour-path FDTD algorithm, is a conducting disk with $2.5 \mathrm{~cm}$ radius and $4 \mathrm{~cm}$ height, and buried $5 \mathrm{~cm}$ under the ground.

\section{A. Effects of the Frequency and the Conductivity}

Fig. 8 presents a set of simulation results of the conducting disk, obtained with the aforementioned heterogeneous ground model and two different GPR units, operating at $200 \mathrm{MHz}$ and $1000 \mathrm{MHz}$. Each of Fig. 8(a)-(f) displays a gray-scale 2-D image of the estimated scattered electric fields (in $\mathrm{V} / \mathrm{m}$ ) and two energy plots presenting the energy distributions with respect to radar position and time. In practice, the scattered fields would be estimated by employing a high-performance detection algorithm. However, for the purposes of this study, it is sufficient to estimate the scattered fields by a simple detection algorithm [2], which requires another simulation to estimate the background signal $\mathrm{D}+\mathrm{G}$. For this purpose, the B-scan is repeated with the same ground model, but without the target. The A-scan measurements of this extra B-scan is averaged to obtain an approximate background signal, which is subtracted from the raw signals to estimate the scattered signals. These scattered signals are merged together in 2-D arrays and normalized, which yield the gray-scale images in Fig. 8. On each of these normalized 2-D arrays, the cumulative energy in each row and column, i.e., at each time step and each radar position, are computed and plotted to the right and in the below of the scattered-field images. The distribution in these energy plots reveal the position and depth of the buried target, if the signals scattered from the target are dominant with respect to other noise signals.

For Fig. 8(a) and (b), where the ground conductivity is $0.05 \mathrm{~S} / \mathrm{m}$, the center frequency of the GPR transmitter is set as $200 \mathrm{MHz}$ and $1000 \mathrm{MHz}$, respectively. Fig. 8(a) and (b) demonstrate that the target signals are dominant for both frequencies, and both GPR units are able to determine the position and depth of the conducting disk. However, when the ground conductivity is increased to $0.2 \mathrm{~S} / \mathrm{m}$, whose $200 \mathrm{MHz}$ and $1000 \mathrm{MHz}$ results are presented in Fig. 8(c) and (d), respectively, the GPR unit operating at $200 \mathrm{MHz}$ can detect the target, whereas the GPR with $1000 \mathrm{MHz}$ center frequency cannot differentiate the target signals from the signals scattered from other heterogeneities. At this ground conductivity, $200 \mathrm{MHz}$ and $1000 \mathrm{MHz}$ center frequency values produce different detection results, demonstrating the effects of the frequency in GPR measurements above highly conducting soils. Finally, Fig. 8(e) and (f) present the $200 \mathrm{MHz}$ and $1000 \mathrm{MHz}$ simulation results of the conducting disk buried in the same heterogeneous ground model, but with $0.8 \mathrm{~S} / \mathrm{m}$ conductivity. These two figures demonstrate that, after a certain level of ground conductivity, none of the GPR units are able to detect the target, since the target signals become invisible with respect to the signals reflected from the surface scatterers and other heterogeneities.

In Section III-B, it is stated that GPR operations at $200 \mathrm{MHz}$ and $1000 \mathrm{MHz}$ do not reveal major differences above a ground with $0.2 \mathrm{~S} / \mathrm{m}$ conductivity, since the corresponding skin-depth values are very close to each other at this conductivity level. The B-scan results given in Fig. 8(c) and (d) do not confirm that statement, since they produce different detection results, as pointed out in the previous paragraph. This dilemma can

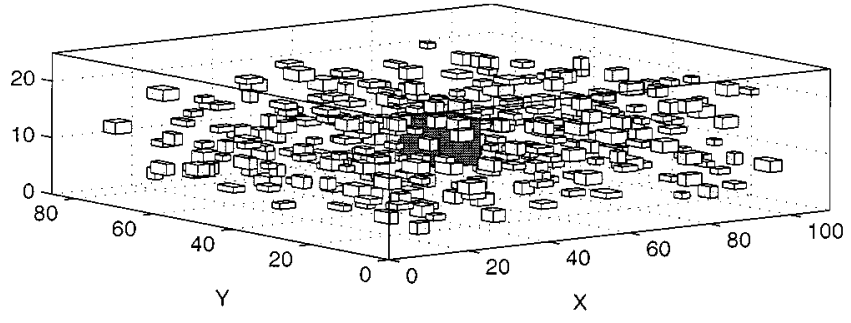

(a)

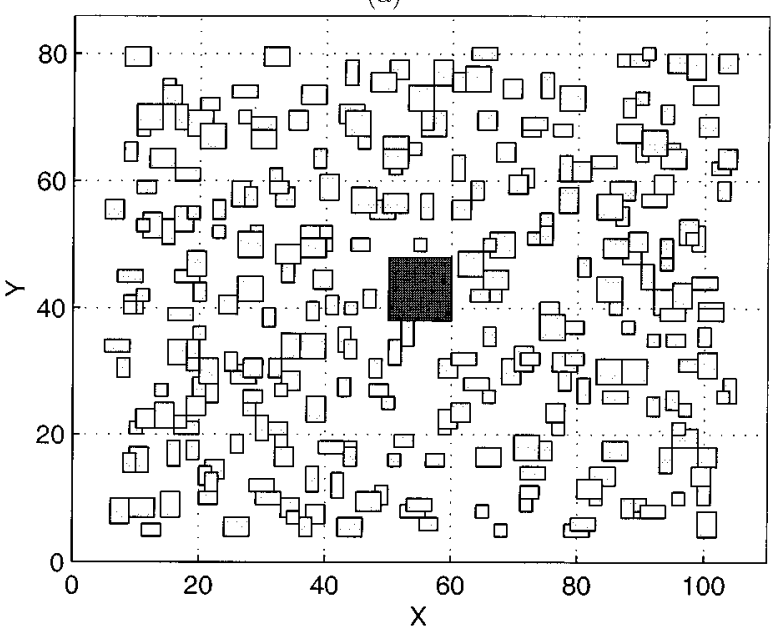

(b)

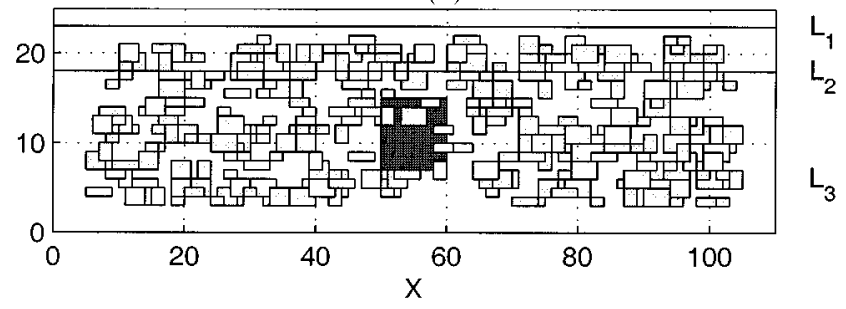

(c)

Fig. 9. Altered heterogeneous ground model, with a background permittivity value of $8 \epsilon_{0}$, but smooth ground-air interface. The second ground level contains 100 highly conducting inhomogeneities and the third level contains 200 scatterers with relatively lower conductivity values. The target is a conducting disk buried $5 \mathrm{~cm}$ deep.

be explained by noting that the conducting heterogeneities embedded in the ground contribute to the overall conductivity of the ground. Although the background conductivity of the ground is $0.2 \mathrm{~S} / \mathrm{m}$, the ground effectively exhibits a more conductive character than $0.2 \mathrm{~S} / \mathrm{m}$, due to these small bodies embedded in it.

\section{B. Effect of the Surface Roughness}

Different detection results obtained with $200 \mathrm{MHz}$ and $1000 \mathrm{MHz}$ center frequencies above a ground model of $0.2 \mathrm{~S} / \mathrm{m}$ do not assert that these two frequency values cause different results at this conductivity level under any circumstances. In [2], it was demonstrated that the removal of surface scatterers facilitates the detection of the target even for very complicated scenarios. Similarly, the removal of surface roughness from the heterogeneous model presented in this paper implies totally different results of detection for the same ground-conductivity values. This fact is demonstrated by another set of simulation 


\section{$200 \mathrm{MHz}$}

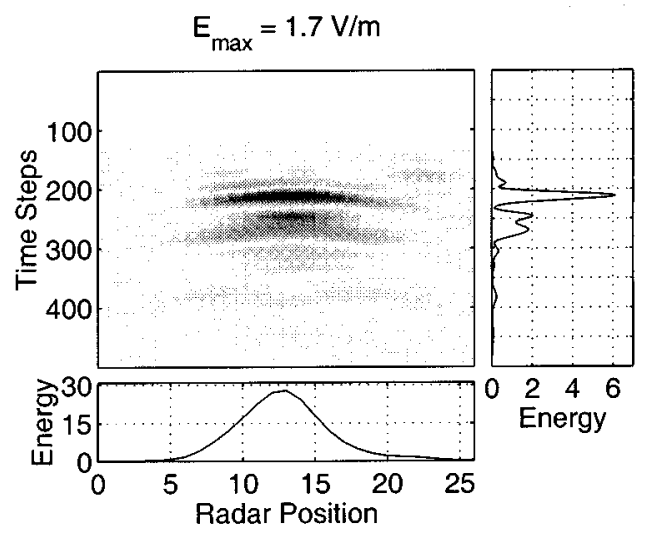

(a)

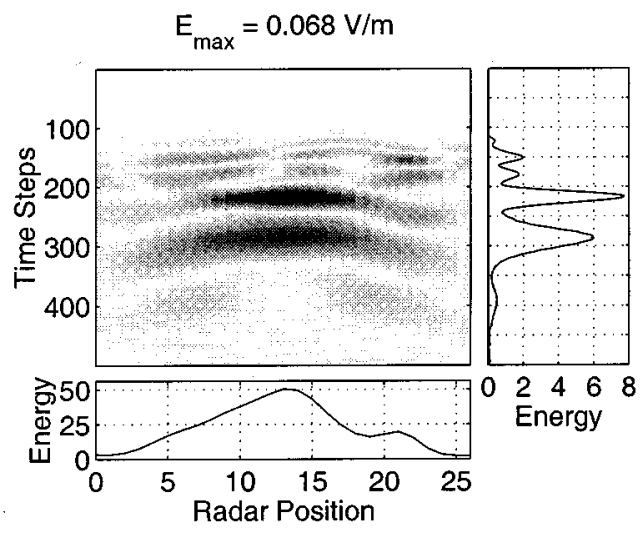

(c)

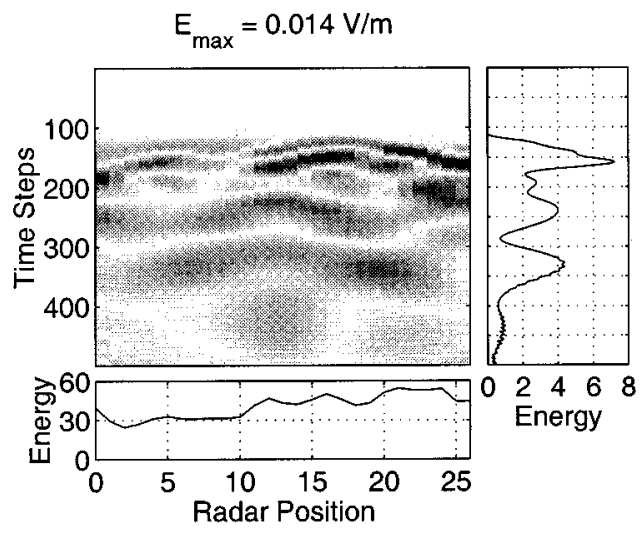

(e)

\section{$1000 \mathrm{MHz}$}

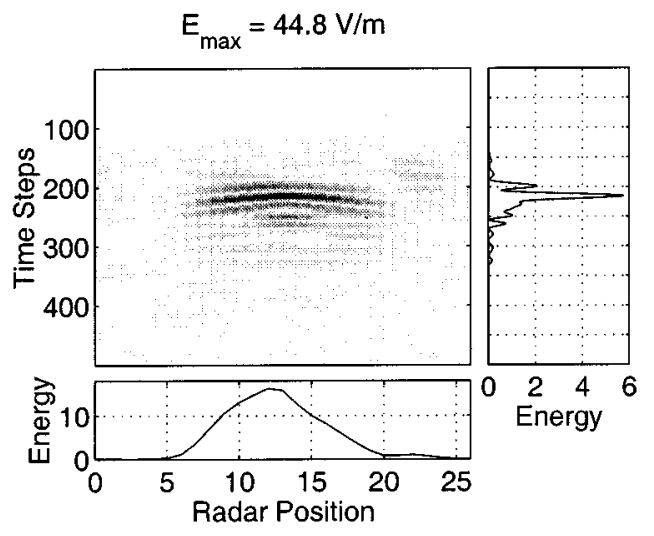

(b)

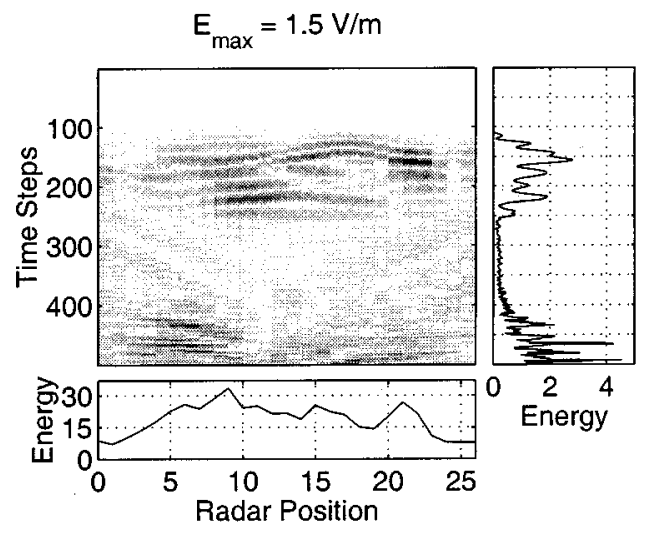

(d)

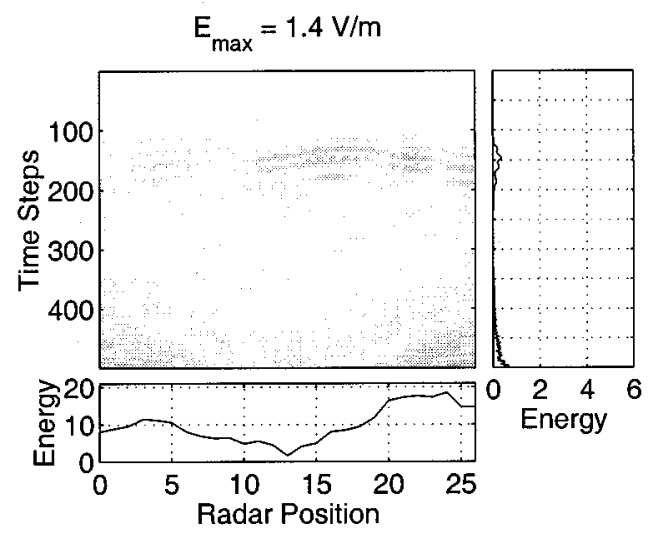

(f)

Fig. 10. Simulation results of a conducting disk buried $5 \mathrm{~cm}$ under the ground-air interface. The permittivity of the ground is $8 \epsilon_{0}$, while the conductivity is 0.2 $\mathrm{S} / \mathrm{m}$ in (a) and (b), $0.8 \mathrm{~S} / \mathrm{m}$ in (c) and (d), and $1.4 \mathrm{~S} / \mathrm{m}$ in (e) and (f). The center frequency of the source signal is $200 \mathrm{MHz}$ in (a), (c), and (e), and $1000 \mathrm{MHz}$ in (b), (d), and (f). The heterogeneous ground model is the similar to the one in Fig. 8, but with surface roughness absent.

results presented in Fig. 10, obtained using a heterogeneous ground model with a smooth surface, as depicted in Fig. 9. The ground model in Fig. 9, which contains 100 highly conducting small scatterers embedded in $L_{2}$, the upper level, and 200 relatively less conducting small scatterers buried in $L_{3}$, the lower level of the ground model, is identical to the ground model in Fig. 7, except for the heterogeneities on the surface
$\left(L_{1}\right)$. In Fig. 10(a) and (b), the ground model has a conductivity of $0.2 \mathrm{~S} / \mathrm{m}$. For the ground model with surface roughness, the two GPR units operating at $200 \mathrm{MHz}$ and $1000 \mathrm{MHz}$ provided different detection results in Fig. 8. However, this time both GPR units with $200 \mathrm{MHz}$ and $1000 \mathrm{MHz}$ center frequencies are firmly able to detect the conducting disk, as demonstrated in Fig. 10(a) and (b). 
$200 \mathrm{MHz}$

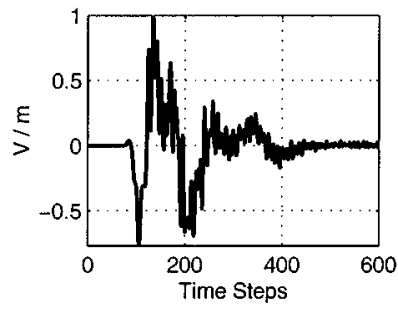

(a)

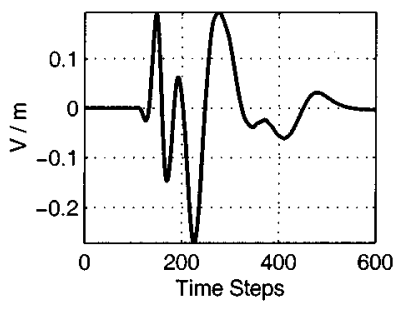

(c)

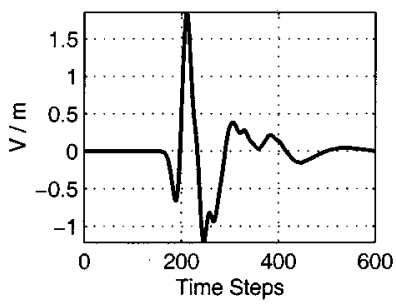

(e)
$1000 \mathrm{MHz}$

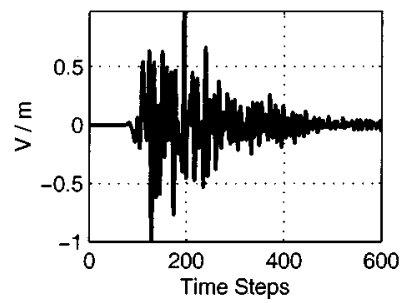

(b)

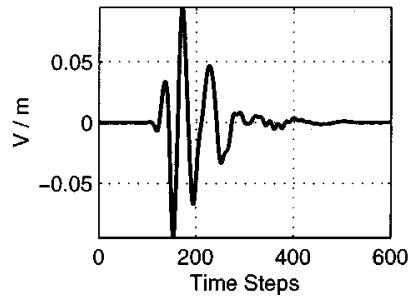

(d)

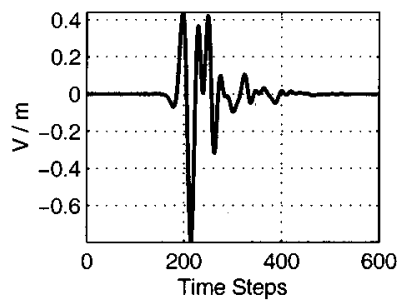

(f)
$200 \mathrm{MHz}$

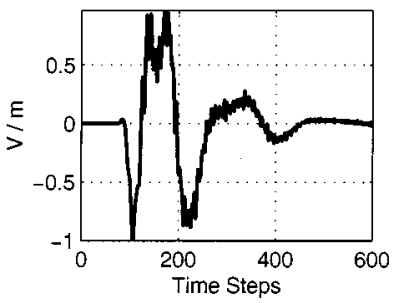

(a)

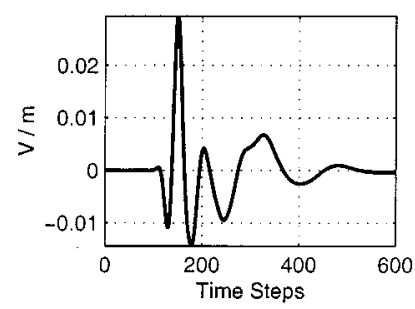

(c)

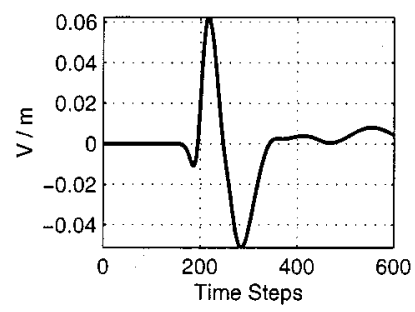

(e)
$1000 \mathrm{MHz}$

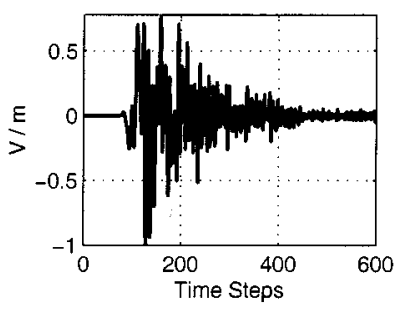

(b)

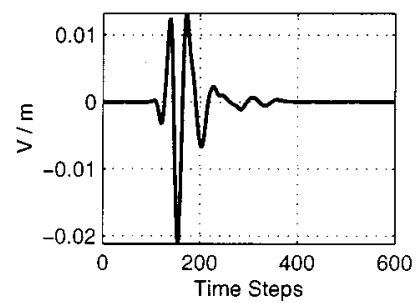

(d)

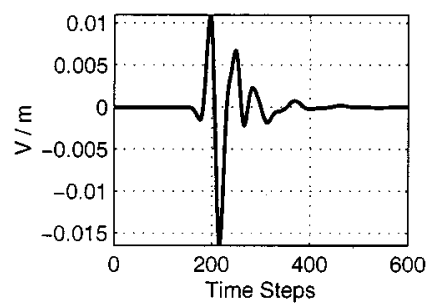

(f)

Fig. 11. Signals scattered from (a) and (b) the surface roughness $\left(L_{1}\right)$, (c) and (d) the heterogeneities embedded in the ground $\left(L_{2}\right)$, and (e) and (f) the target. The permittivity and the conductivity of the ground are $8 \epsilon_{0}$ and $0.2 \mathrm{~S} / \mathrm{m}$, respectively. The GPR unit operates at $200 \mathrm{MHz}$ in (a), (c), and (e), and 1000 $\mathrm{MHz}$ in (b), (d), and (f). The scattered signals at each center frequency are normalized with respect to the largest noise signal, which happens to be the scattering from the surface roughness.

The removal of the surface roughness provides a new background signal and a new noise level when that background signal is subtracted from the total received signal. The detectability of the target in this new model is determined by the energy of the target signals relative to the energies of the new noise signals. Figs. 11 and 12 present four additional sets of simulation results, which demonstrate the scattered-signal amplitudes from surface roughness, buried heterogeneities, and the buried target. These scattered-field signals are obtained with the simulations of ground models containing only the surface roughness, only the embedded heterogeneities, and only the target. Simulation results have shown that the signals scattered from the heterogeneities, embedded in the lower level of the ground, are very weak with respect to the other scattered-field signals. Therefore, only the $L_{1}, L_{2}$, and the target signals are presented in Figs. 11 and 12. Figs. 11 and 12 present simulation results obtained with $0.2 \mathrm{~S} / \mathrm{m}$ and $0.8 \mathrm{~S} / \mathrm{m}$ ground conductivity, and $200 \mathrm{MHz}$ and $1000 \mathrm{MHz}$ operating frequency. Moreover, in these figures, the $L_{1}, L_{2}$, and target signals are normalized with respect to the amplitude of the largest noise component

Fig. 12. Signals scattered from (a) and (b) the surface roughness $\left(L_{1}\right)$, (c) and (d) the heterogeneities embedded in the ground $\left(L_{2}\right)$, and (e) and (f) the target. The permittivity and the conductivity of the ground are $8 \epsilon_{0}$ and $0.8 \mathrm{~S} / \mathrm{m}$, respectively. The GPR unit operates at $200 \mathrm{MHz}$ in (a), (c), and (e), and 1000 $\mathrm{MHz}$ in (b), (d), and (f). The scattered signals at each center frequency are normalized with respect to the largest noise signal, which happens to be the scattering from the surface roughness.

in the corresponding scenario, which is the $L_{1}$ signal, i.e., the signal scattered from the surface roughness.

Fig. 11 presents the simulation results obtained with the ground model of $0.2 \mathrm{~S} / \mathrm{m}$ conductivity. Comparison of Fig. 11(e) and (f) to 11(a) and (b) reveals that the target signal obtained with GPR unit of $1000 \mathrm{MHz}$ is almost two times weaker than the target signal received by the GPR unit operating at $200 \mathrm{MHz}$. In Fig. 12, where the ground conductivity is raised to $0.8 \mathrm{~S} / \mathrm{m}$, this ratio is larger than four, as demonstrated by Fig. 12(e) and (f). Therefore, detection at $1000 \mathrm{MHz}$ can be expected to be more difficult than detection at $200 \mathrm{MHz}$ for $0.8 \mathrm{~S} / \mathrm{m}$ conductivity, as demonstrated in Fig. 10(b) and (c), and explained in the below. Figs. 11 and 12 also show that the $L_{2}$ signals are much weaker than the $L_{1}$ signals, and the signal-to-noise ratio increases significantly when the surface degenerations are removed.

Thus, although both GPR units were able to detect the target at the $0.2 \mathrm{~S} / \mathrm{m}$ conductivity of the ground in Fig. 7, for the ground model in Fig. 9, there will be a new threshold of conductivity, 
where $200 \mathrm{MHz}$ and $1000 \mathrm{MHz}$ center frequencies produce different results. Such a case is presented in Fig. 10(c) and (d), where the ground conductivity is set as $0.8 \mathrm{~S} / \mathrm{m}$. Fig. 10(c) and (d) demonstrate that the GPR unit operating at $200 \mathrm{MHz}$ detects the buried target, while the one operating at $1000 \mathrm{MHz}$ cannot. Similar to the ground model with surface degenerations, it is possible to find a conductivity level, where none of the GPR units can make a detection. In Fig. 10(e) and (f), where the ground conductivity is raised to $1.4 \mathrm{~S} / \mathrm{m}$, neither of the operating frequencies, $200 \mathrm{MHz}$ and $1000 \mathrm{MHz}$, can make an acceptable detection of the buried conducting disk.

\section{CONCLUding REMARKS}

The 3-D FDTD method employing the PML ABC for lossy and layered media is used to investigate the behavior of GPR signals for different operating frequencies and ground models. The GPR unit is modeled as a transmitter-receiver pair isolated by conducting shields and absorbers simulated by PML walls. The ground is modeled by a heterogeneous lossy dielectric halfspace and the target is modeled by a conducting disk.

Electromagnetic waves with different frequencies undergo different amounts of decay when propagating in a lossy medium. The amount of this decay is determined by the skin depth of the medium, which depends on the permittivity, permeability, and the conductivity of the medium, as well as the frequency of the propagating wave. However, the rate of change of the decay with respect to the frequency may be very small when the conductivity value is smaller than a certain value. Real-life soils do not exhibit very large conductivity characteristics if they are not extremely humid. For such humid soils, the variation of the GPR operating frequency may or may not change the detection result, depending on the amount of noise in the total received signal.

In this paper, the simulation results of GPR units operating between $200 \mathrm{MHz}$ and $1000 \mathrm{MHz}$ are given for heterogeneous soil models with conductivity values between $0.1 \mathrm{~S} / \mathrm{m}$ and $1.0 \mathrm{~S} / \mathrm{m}$. It is shown that two GPR models, operating at $200 \mathrm{MHz}$ and $1000 \mathrm{MHz}$, produce different detection results for some of the scenarios and produce the same result for some others. It is demonstrated that the conductivity of the ground, the amount and character of the ground heterogeneity, and the depth and the electrical parameters of the target are effective on this detection result. Although the conclusions of this paper are based on synthetic data, similar conclusions are drawn in [22], where it is experimentally shown that, for a specific soil type, there exists an optimum frequency for which the incident waves experience minimum loss during propagation.

\section{REFERENCES}

[1] F. L. Teixeria, W. C. Chew, M. Straka, and M. L. Oristaglio, "Finite-difference time-domain simulation of ground-penetrating radar on dispersive, inhomogeneous, and conductive soils," IEEE Trans. Geosci. Remote Sensing, vol. 36, pp. 1928-1937, Nov. 1998.

[2] L. Gürel and U. Oğuz, "Simulations of ground-penetrating radars over lossy and heterogeneous grounds," IEEE Trans. Geosci. Remote Sensing, vol. 39, pp. 1190-1197, June 2001.
[3] F. D. Hastings, J. B. Schneider, and S. L. Broschat, "A Monte-Carlo FDTD technique for rough surface scattering," IEEE Trans. Antennas Propagat., vol. 43, pp. 1183-1191, Nov. 1995.

[4] J. M. Bourgeois and G. S. Smith, "A complete electromagnetic simulation of the separated-aperture sensor for detecting buried land mines," IEEE Trans. Antennas Propagat., vol. 46, pp. 1419-1426, Oct. 1998.

[5] K. S. Yee, "Numerical solution of initial boundary value problems involving Maxwell's equations in isotropic media," IEEE Trans. Antennas Propagat., vol. 14, pp. 302-307, May 1966.

[6] M. Moghaddam, E. J. Yannakakis, W. C. Chew, and C. Randall, "Modeling of the subsurface interface radar," J. Electromagn. Waves Applicat., vol. 5, no. 1, pp. 17-39, 1991.

[7] J. M. Bourgeois and G. S. Smith, "A fully three-dimensional simulation of a ground-penetrating radar: FDTD theory compared with experiment," IEEE Trans. Geosci. Remote Sensing, vol. 34, pp. 36-44, Jan. 1996.

[8] K. Demarest, Z. Huang, and R. Plumb, "An FDTD near- to far-zone transformation for scatterers buried in stratified grounds," IEEE Trans. Antennas Propagat., vol. 44, pp. 1150-1157, Aug. 1996.

[9] U. Oğuz and L. Gürel, "Modeling of ground-penetrating-radar antennas with shields and simulated absorbers," IEEE Trans. Antennas Propagat., vol. 49 , pp. $1560-1567$, Nov. 2001

[10] R. V. de Jongh, L. P. Ligthart, I. V. Kaploun, and A. D. Schukin, "Design and analysis of new GPR antenna concepts," in Proc. GPR'98, 7th Int. Conf. Ground-Penetrating Radar. Lawrence, KS, May 1998.

[11] Y. Nishioka, O. Maesima, T. Uno, and S. Adachi, "FDTD analysis of resistor loaded bow-tie antennas covered with ferrite coated conducting cavity for sub-surface radar," IEEE Antennas Propagat., vol. 47, pp. 970-977, June 1999.

[12] J. P. Berenger, "A perfectly matched layer for the absorption of electromagnetic waves," J. Comput. Phys., pp. 185-200, Oct. 1994.

[13] D. S. Katz, E. T. Thiele, and A. Taflove, "Validation and extension to three dimensions of the Berenger PML absorbing boundary condition for FD-TD meshes," IEEE Microwave Guided Wave Lett., vol. 4, pp. 268-271, Aug. 1995.

[14] J. Fang and Z. Wu, "Generalized perfectly matched layer for the absorption of propagating and evanescent waves in lossless and lossy media," IEEE Trans. Microwave Theory Tech., vol. 44, pp. 2216-2222, Dec. 1996.

[15] D. N. Buechler, D. H. Roper, C. H. Durney, and D. A. Christensen, "Modeling sources in the FDTD formulation and their use in quantifying source and boundary condition errors," IEEE Trans. Microwave Theory Tech., vol. 43, pp. 810-814, Apr. 1995.

[16] W. C. Chew and W. H. Weedon, "A 3D perfectly matched medium from modified Maxwell's equations with stretched coordinates," Microwave Opt. Technol. Lett., vol. 7, pp. 599-604, Sept. 1994.

[17] N. Peplinski, F. Ulaby, and M. C. Dobson, "Dielectric properties of soils in the $0.3-1.3 \mathrm{GHz}$ range," IEEE Trans. Geosci. Remote Sensing, vol. 33, pp. 803-807, Mar. 1995.

[18] D. J. Daniels, Surface-Penetrating Radar. London, U.K.: IEE, 1996, ch. 2 , pp. 100-150.

[19] D. K. Cheng, Field and Wave Electromagnetics. Reading, MA: Addison-Wesley, 1983, ch. 8, p. 320.

[20] A. Taflove, Computational Electrodynamics: The Finite-Difference Time-Domain Method. Boston, MA: Artech House, 1995.

[21] T. G. Jurgens, A. Taflove, K. Umashankar, and T. G. Moore, "Finite-difference time-domain modeling of curved surfaces," IEEE Trans. Antennas Propagat., vol. 40, pp. 357-366, Apr. 1992.

[22] P. Hoekstra and A. Delaney, "Dielectric properties of soils at UHF and microwave frequencies," J. Geophys. Res., vol. 79, no. 11, pp. 1699-1708, 1974.

Uğur Oğuz was born in Ankara, Turkey, in 1973. He received the B.Sc. and M.Sc. degrees, both in electrical engineering, from Bilkent University, Ankara, Turkey, in 1994 and 1997, respectively.

From August 1997 to October 1998, he served in the Turkish Army, working as a Database Manager. From November 1998 to May 2002, he was a Research Engineer in the Department of Electrical and Electronics Engineering, Bilkent University. Since June 2002, he has been with the National Research Institute of Electronics and Cryptology (Tübitak-Uekae), Ankara. His research interests include time-domain methods in computational electromagnetics and their applications to geophysical problems. 
Levent Gürel (S'87-M'92-SM'97) was born in İzmir, Turkey, in 1964. He received the B.Sc. degree from the Middle East Technical University (METU), Ankara, Turkey, in 1986, and the M.S. and Ph.D. degrees from the University of Illinois at Urbana-Champaign (UIUC), in 1988 and 1991, respectively, all in electrical engineering.

He joined the Thomas J. Watson Research Center, International Business Machines Corporation, Yorktown Heights, NY, in 1991, where he was a Research Staff Member working on electromagnetic compatibility (EMC) problems related to electronic packaging, on the use of microwave processes in the manufacturing and testing of electronic circuits, and on the development of fast solvers for interconnect modeling. He became Associate Professor in 1993. Since 1994, he has been a faculty member in the Department of Electrical and Electronics Engineering, Bilkent University, Ankara. He was a Visiting Associate Professor at the Center for Computational Electromagnetics (CCEM), UIUC, for one semester in 1997. His research interests include the development of fast algorithms for computational electromagnetics (CEM) and the application thereof to scattering and radiation problems involving large and complicated scatterers, antennas and radars, frequency-selective surfaces, and high-speed electronic circuits. He is also interested in the theoretical and computational aspects of electromagnetic compatibility and interference analyses. Ground-penetrating radars and other subsurface-scattering applications are also among his current research interests.

Dr. Gürel is currently serving as the Chairman of the AP/MTT/ED/EMC Chapter of the IEEE Turkey Section. 